\title{
Imagem de Destinos Turísticos: um estudo sobre as publicações brasileiras ${ }^{1}$
}

\author{
Destination Tourism Image: a Brazilian publications study
}

\section{Imagen de Destinos Turísticos: un estudio sobre las publicaciones brasileñas}

Elaine Cristina Borges Scalabrini ${ }^{2}$

Paula Cristina Remoaldo ${ }^{3}$

Júlia M. Lourenço ${ }^{4}$

\begin{abstract}
Resumo
Os estudos referentes ao turismo dedicam-se à compreensão de diferentes temas, sendo que um bastante analisado à escala internacional é a questão da imagem de um destino turístico. $\mathrm{O}$ interesse por este tema é percebido em diversas áreas do conhecimento, como a sociologia e o marketing. No Brasil, há diversos pesquisadores dedicando-se à imagem dos destinos turísticos. Assim, buscando compreender de que forma este tema tem sido trabalhado no Brasil, este estudo de caráter bibliográfico teve como objetivo analisar e compreender as publicações sobre imagem de destinos turísticos em periódicos brasileiros, nos últimos seis anos (2008-2014). A partir de um levantamento dos artigos publicados neste período, usando como ferramenta de busca o site "Publicações de Turismo", foram identificados vinte e oito artigos. A análise permitiu verificar que os estudos estão concentrados na compreensão da imagem de um determinado destino. Os artigos analisados são predominantemente estudos empíricos e há um equilíbrio entre os de caráter quantitativo e qualitativo. No que diz respeito à bibliografia, foi possível identificar que os autores brasileiros que têm trabalhado com o tema de imagem de destinos, já buscam bibliografias internacionais para fundamentar os seus estudos. Também nos trabalhos sobre este tema, identificou-se uma maior maturidade dos autores no que diz respeito à utilização das ferramentas estatísticas. Alguns estudos fazem uma análise aprofundada dos estudos internacionais e aplicam estas teorias no Brasil. Conclui-se que este tema tem sido estudado com maior profundidade no país, se comparado com os temas como o da percepção de residentes.
\end{abstract}

Palavras-chave: Imagem; Destinos turísticos; Publicações brasileiras; Análise metodológica.

\footnotetext{
${ }^{1}$ Trabalho apresentado no Fórum ABRATUR-15 realizado de 08 a 10 de junho de 2015 na Escola de Artes, Ciências e Humanidades da Universidade de São Paulo e indicado como melhor trabalho do evento.

${ }^{2}$ Professora Adjunta da Universidade da Região de Joinville e Doutoranda em Geografia pela Universidade do Minho. Brasil. E-mail:elaine.scalabrini@univalle.br

${ }^{3}$ Professora Associada com Agregação do Departamento de Geografia da Universidade do Minho, CoCoordenadora do Grupo de Investigação em Espaço e Representação (SpaceR) do Laboratório de Paisagens, Património e Território (Lab2PT) da Universidade do Minho. Doutora em Geografia Humana. Portugal. E-mail: cris.remoaldo@gmail.com

${ }^{4}$ Professora Auxiliar do Departamento de Eng. Civil da EEUM e Investigadora do Centro Território, Ambiente e Construção (C-TAC). Doutora em Engenharia Civil pela Universidade Técnica de Lisboa. Portugal. E-mail: jloure@civil.uminho.pt
} 


\begin{abstract}
Tourism related studies encompass several research topics including destination tourism image. This issue is perceived in different areas of knowledge such as sociology and marketing. In Brazil, many researchers have tried to understand the destination tourism image of the country. In order to understand how this topic has been worked in Brazil, this bibliographical study aimed to analyze and understand the image content about tourist destinations in Brazilian journals in the last six years (2008-2014). From a survey of articles published in this period, using as search the website "Tourism Publications," twenty-eight articles were identified. The analysis showed that the studies are focused on understanding the image of a destination in particular, especially at the country image level. The articles analyzed are predominantly empirical studies and there is a balance between quantitative and qualitative. With regard to the literature, we found that the Brazilian authors who have worked with the picture theme destinations, already seeking international bibliographies to support their studies. Also in the works on this topic, it was identified better maturity of the authors regarding the use of statistical tools. Some studies make a good analysis of international studies and apply these theories in Brazil. It was concluded that this topic has been studied in greater depth in the country, compared to subjects such as perception of residents.
\end{abstract}

Keywords: Image; Tourism destination;Brazilian publications; Methodological analysis.

\title{
Resumen
}

Estudios relacionados con el turismo están dedicados a la comprensión de los diferentes temas, y uno bastante analizado es la imagen de un destino turístico. El interés en este tema se percibe en diferentes áreas del conocimiento, como la sociología y la comercialización. En Brasil, ya hay varios investigadores dedicados a la imagen de los destinos turísticos. Por lo tanto, tratando de entender cómo este tema ha estado trabajando en Brasil, este estudio bibliográfico es destinado a analizar y comprender los estudios brasileños sobre la imagen de los destinos turísticos en revistas brasileñas en los últimos seis años (2008-2014). A partir de una encuesta realizada a los artículos publicados en este período, utilizando como motor de búsqueda del sitio web "Publicaciones Turismo" se identificaron veintiocho artículos. El análisis mostró que los estudios se centran en la comprensión de la imagen de un determinado destino. Los artículos analizados son predominantemente estudios empíricos y hay un equilibrio entre lo cuantitativo y cualitativo. En cuanto a la literatura, puede se decir que los autores brasileños que han trabajado con la temática de imagen de destinos turísticos han utilizado bibliografías internacionales para apoyar sus estudios. También se identificó una mayor madurez de los autores en relación con el uso de herramientas estadísticas. Algunos estudios hacen un análisis exhaustivo de los estudios internacionales y se aplican estas teorías en Brasil. Se concluye que este tema ha sido estudiado en mayor profundidad en el país, en comparación con cuestiones tales como la percepción de los residentes.

Palabras clave: Imagen; Destinos turísticos; Publicaciones brasileñas; Análisis metodológicas. 


\section{Introdução}

Os estudos sobre turismo têm sido aprofundados, principalmente nos últimos quarenta anos. Vários autores têm-se dedicado nos estudos conceituais e empíricos de diferentes temas relacionados com a atividade turística, tais como a motivação de turistas, o planejamento da atividade turística, os equipamentos turísticos, a percepção de residentes e a imagem de destinos turísticos.

Especificamente sobre imagem de destinos turísticos, é perceptível que este é um tema de grande interesse por parte dos pesquisadores, principalmente, por que, assim como o turismo, os estudos sobre a imagem de destinos são interdisciplinares, ou seja, analisados em diferentes áreas do conhecimento como a antropologia, a sociologia, a geografia, a psicologia e o marketing (GALLARZA, et al., 2002). Estes estudos também podem estar diretamente relacionados com a questão da segmentação de mercado ou a percepção que os visitantes têm de um destino. Echtner e Ritchie (2003) e Buosi et al. (2014) demonstram que as pesquisas sobre imagem de destinos estão diretamente relacionados com a estratégias de marketing e Chagas (2009) afirma que o sucesso no desenvolvimento de um destino turístico está relacionado com a imagem que o mesmo assume junto dos seus visitantes ou potenciais visitantes. Ainda é possível afirmar que a imagem de um local pode ser determinante nos processos decisórios e no planejamento do turismo no destino (CHOI, et al., 2007; CHAGAS, 2009; RYAN e AICKEN, 2010).

Com base nestes pressupostos, os estudos sobre imagem de destinos turísticos, têm-se dedicado a compreender empiricamente, a imagem de diferentes destinos existentes à escala internacional. Outros estudos, dedicam-se à compreensão conceitual do tema, tanto no Brasil, quanto no exterior (GALLARZA, et al., 2002; CHAGAS, 2009; BREA e CARDOSO, 2011). No Brasil também é pertinente destacar a publicação de artigos sobre o tema de imagem de destinos turísticos que incluem a proposição e mensuração de modelos.

Com o objetivo de analisar e compreender as publicações sobre imagem de destinos turísticos em periódicos brasileiros, nos últimos seis anos (2008-2014), foi realizado o presente estudo usando fontes secundárias com acesso a artigos compilados no site "Publicações de Turismo" e, após critérios de escolha apresentados no item "Aspectos metodológicos" do presente artigo, foi realizada uma análise da metodologia utilizada em vinte e oito trabalhos publicados em diferentes periódicos nacionais. 
A partir da análise das publicações brasileiras verificou-se que os estudos tentam compreender a imagem de um determinado destino, focando-se principalmente na imagem do país ou de cidades como São Paulo, Curitiba e Rio de Janeiro. Os artigos são predominantemente de natureza empírica e em relação à abordagem há um equilíbrio entre os de caráter quantitativo e qualitativo. No que diz respeito à bibliografia, foi possível identificar que os autores brasileiros que têm trabalhado a temática da imagem de destinos, utilizam literatura internacional para fundamentar os seus estudos. Também é perceptível uma maior maturidade dos autores no que diz respeito à utilização das ferramentas estatísticas, podendo ser citadas a análise multivariada e a análise de regressão múltipla. Outro aspecto relevante é que alguns estudos fazem uma análise aprofundada dos estudos internacionais e as teorias são aplicadas no Brasil.

Este artigo, ainda apresenta uma breve análise sobre os estudos de imagem de destinos turísticos e alguns modelos desenvolvidos para a mensuração desta, tanto em destinos internacionais, quanto nacionais. Tal revisão é importante para verificar quais são os principais conceitos desenvolvidos, principalmente no exterior e que servirão como base à análise dos artigos brasileiros.

\section{Estudos sobre Imagem de Destinos Turísticos}

No que diz respeito à conceituação de imagem de destinos turísticos, a abordagem tem sido diferenciada. Chagas (2009) afirma que a imagem é a representação que os consumidores têm de determinado destino. Konecnik (2005) defende que a imagem é um conjunto de impressões que os turistas têm de um local onde não residem e ainda destaca a dificuldade na delimitação de uma imagem, já que é uma questão subjetiva, ou seja, os diferentes grupos podem percepcionar um destino de acordo com as suas características sócio demográficas e as suas experiências.

No que diz respeito a estes pressupostos, percebe-se que, muitas vezes, o planejamento de marketing impõe uma imagem que não é a que o residente tem do seu município. Neste sentido, Brea e Cardoso (2011) defendem a necessidade de um consenso entre comunidade e marca do destino, visto que estes são os responsáveis pela recepção do turista e devem ser receptivos ao turismo. Ainda sobre a imagem de residentes Lynch (1960) defende que estes têm uma imagem impregnada de memórias, pois constróem relações com diferentes partes da 
cidade onde vivem. Sendo assim, tal refletir-se-á diretamente nos aspectos turísticos de um município e mostra a importância de como o residente percebe a sua cidade.

Na busca por turistas que consumam um destino, os promotores utilizam uma série de códigos (Quadro 1) para a formação de uma imagem, conforme observado por Pérez (2009).

Quadro 1 - Elementos relevantes na formação da imagem de destinos turísticos

\begin{tabular}{l|l}
\hline Código & Forma de representação \\
\hline Psicológico & $\begin{array}{l}\text { Utilização de representações que evoquem emoções ou revivam } \\
\text { experiências }\end{array}$ \\
\hline Estético & O contorno é representado como uma obra de arte antrópica ou física \\
\hline Inconsciente & Utilização de mensagens subliminais \\
\hline Mítico & $\begin{array}{l}\text { Referência à fantasia, ao irracional, ao paraíso perdido, ao arcaico ou ao } \\
\text { progresso }\end{array}$ \\
\hline Estratégico & $\begin{array}{l}\text { Apresentação de uma série de valores e uma determinada posição } \\
\text { estratégica }\end{array}$ \\
\hline Geográfico-humano & Exposição épica do clima, da geomorfologia, dos habitantes, etc. \\
\hline Infra-estrutural & Como fazer a viagem e comunicar com o destino \\
\hline
\end{tabular}

Fonte: adaptado de Pérez (2009).

O que parece ser um consenso entre vários pesquisadores é que a formação da imagem de um destino turístico está relacionada diretamente com dois fatores a saber: os de estímulo e os pessoais (BALOGLU e MCCLEARY, 1999; CHAGAS, et al., 2013b). Ainda neste sentido é possível verificar que existem as percepções cognitivas, relacionadas com os atributos percepcionados de determinado destino e as afetivas que referem-se aos sentimentos que se têm em relação ao local. É comum firmar que a imagem do destino depende de uma avaliação cognitiva de objetos e as respostas afetivas são formadas a partir das respostas cognitivas. Portanto, a imagem é formada do resultado das duas percepções (BALOGLU E MACCLEARY, 1999).

Corroborando esta afirmação, Vareiro e Ribeiro (2006) afirmam que o processo de formação de imagem depende dos fatores exógenos, que são aqueles diretamente relacionados com o consumidor, responsáveis pela formação da imagem projetada e dos fatores endógenos que são os que estão relacionados com as informações que se tem de um destino e são responsáveis pela formação da imagem desenhada que se tem de um determinado destino. O ideal é que a imagem real que se tem de um destino seja a mais próxima entre a projetada e a desenhada.

Com base nisso, diferentes tipos de imagem podem ser estabelecidos, conforme apresentado no Quadro 2. 


\begin{tabular}{l|l}
\hline \multicolumn{2}{c}{ Quadro 2 - Tipos de imagens de destinos turísticos } \\
\hline Tipo de Imagem & Caracterização \\
\hline Demasiado atraente & Destinos que possuem atratividade excessiva. \\
\hline Positiva/ atrativa & $\begin{array}{l}\text { Favorece o destino, estimula a vinda de turistas ao local. Não há necessidade de } \\
\text { mudança na imagem, mas é necessária uma maior divulgação para mercados } \\
\text { potenciais. }\end{array}$ \\
\hline Contraditória & Possibilita diferentes perspectivas na análise da imagem. \\
\hline Pobre/ fraca & $\begin{array}{l}\text { Baixo potencial atrativo, seja por falta de divulgação ou por falta de recursos } \\
\text { turísticos. }\end{array}$ \\
\hline Neutra & Não provoca nenhum sentimento de atração ou repulsa no consumidor. \\
\hline Negativa/ repulsiva & $\begin{array}{l}\text { Os aspectos desfavoráveis apresentam-se de maneira intensa junto ao público-alvo } \\
\text { do destino. }\end{array}$ \\
\hline Mista & $\begin{array}{l}\text { Apresenta um mix de componentes atrativos e repulsivos. Desperta interesse e } \\
\text { ressalvas. }\end{array}$ \\
\hline Estereotipada & O destino torna-se um tipo de 'ícone' de representação. \\
\hline Distorcida/ confusa & $\begin{array}{l}\text { Apresenta supervalorização de aspectos desfavoráveis, não necessariamente } \\
\text { expressando a verdade. }\end{array}$ \\
\hline Fonte: adaptado de Chagas
\end{tabular}

Fonte: adaptado de Chagas (2009).

A compreensão dos diferentes tipos de imagem possibilita que a imagem de um destino representa tanto para os seus residentes como para os turistas que optam por visitar o destino.

É relevante destacar, novamente, que a maioria dos estudos estão voltados para o turista. Echtner e Ritchie (2003), ao desenvolverem uma análise sobre os estudos relacionados com o tema, identificaram que a formação da imagem de um destino consiste na combinação de sete fatores:

- Acúmulo de imagens mentais sobre experiências de férias;

- Modificação da imagem por meio de informações obtidas;

- Decisão de fazer a viagem para o destino;

- Viagem para o destino;

- Participação no destino;

- Retorno para casa;

- Modificação da imagem baseada na experiência.

Ao apresentar estas etapas, afirmam que após a visita efetivada a imagem fica mais realista, complexa e diferenciada. Esta conclusão permite uma importante reflexão para os estudos relacionados com os residentes, podendo-se considerar que o residente participa ativamente no destino, logo a sua imagem pode ser mais realista do que a do turista. Para fundamentar esta afirmação, Alves (2003) argumenta que a relação pessoal que cada indivíduo tem com o 
espaço, ou seja a interação e as suas próprias experiências fortalecem o significado dado ao lugar e a imagem que este constrói.

Diante destes fatos, os pesquisadores que se têm debruçado sobre esta temática têm desenvolvido modelos para a análise e identificação de imagens turísticas, modelos tais como os de Baloglu e McCleary (1999), Echtner e Ritchie (2003), Chagas (2009), que exploram a relação entre os fatores pessoais, os fatores de estímulo e a imagem do destino. Importa, mais uma vez, sobressair que, estes estudos têm como foco principal o turista.

Os modelos de definição de imagem estão, na maioria das vezes, relacionados com as percepções afetivas e cognitivas dos pesquisados (BALOGLU E MCCLEARY, 1999, ECHTNER E RITCHIE, 2003, CHAGAS, 2009). A mensuração é feita por meio de um questionário composto de frases afirmativas e, o inquirido deve optar por um nível numa escala de Likert, geralmente de 5 níveis.

Tendo por base estudos anteriores realizados para analisar publicações referentes ao tema, foram identificados os estudos realizados por Gallarza et al. (2002) que apresentaram uma revisão e discussão sobre os principais conceitos e métodos de mensuração de imagens de destinos. No Brasil, Chagas (2009) analisou os principais modelos internacionais de formação de imagem de um destino turístico e Brea e Cardoso (2011) também apresentaram uma reflexão sobre as principais investigações sobre o tema.

Por fim, ao analisar os diferentes estudos realizados, pode-se deduzir que tendo o residente uma percepção cognitiva positiva a respeito do lugar onde vive, a imagem será positiva e logo, ele terá orgulho de divulgar o seu destino, recebendo bem o turista e vendo o turismo como algo positivo para o lugar.

\section{Aspectos Metodológicos}

Para atingir os objetivos propostos neste estudo, foi realizado, inicialmente, um levantamento dos artigos publicados sobre imagem de destinos turísticos no Brasil. Este levantamento foi realizado durante o mês de janeiro de 2015. Para tal, foi utilizado o site "Publicações de Turismo" (http://www.publicacoesdeturismo.com.br/) onde estão indexados trinta periódicos nacionais e mais de 1700 títulos de livros. 
É importante evidenciar que foram utilizados somente artigos publicados em periódicos do Brasil, não tendo sido considerados trabalhos apresentados em eventos relacionados com a atividade turística, pois os mesmos não estão indexados na referida base de dados.

Para a pesquisa inicial, foram utilizados os termos "imagem de destinos turísticos" e "imagem" e selecionados os que apresentavam no seu título estes termos. Em seguida, após leitura do resumo dos artigos, foram selecionados os artigos que apresentavam como objetivo identificar a imagem de determinado destino turístico, conforme apresentado no Quadro 3. Foram excluídos artigos que abordavam a intenção de compras, ou formação de imagem de equipamentos turísticos, tais como hotéis. Nesta etapa, obteve-se um total de vinte e oito artigos para a realização da análise proposta.

Quadro 3 - Número de artigos alocados na base "Publicações de Turismo"
\begin{tabular}{l|c}
\hline Termo & Número total de artigos \\
\hline Imagem & 136 \\
\hline Imagem de destinos turísticos & 21 \\
\hline Total de artigos selecionados & $\mathbf{2 8}$ \\
\hline Fonte: elaboração própria.
\end{tabular}

Após a leitura do material recolhido, os dados foram organizados numa base de dados que contemplou as seguintes variáveis: ano de publicação, periódico de publicação, objeto de estudo, natureza do estudo, estratégia de pesquisa, origem dos dados, tamanho e tipologia da amostra, coleta e análise dos resultados, tratamento estatístico e bibliografia. É importante ressaltar que estas variáveis foram utilizadas por Scalabrini et al. (2014) numa análise sobre publicações relacionadas com a percepção de residentes e também são similares às utilizadas no estudo de Kovacs et al. (2012) que analisou as publicações sobre o turismo no Brasil. Outra obra que foi utilizada como base para a análise das publicações brasileiras foi a de Gallarza et al. (2002) que revisou vinte e cinco estudos sobre o tema de imagens de destinos turísticos, publicadas em diferentes periódicos no período de 1979 a 1999.

Além de Kovacs et al. (2012), outros autores já desenvolveram estudos com o objetivo de analisar as publicações do turismo em algum tema específico. Assim, os trabalhos de Leal (2001), Rejowski (2010), Panosso Netto e Calciolari (2011), Freitag et al. (2011) e Rosvadoskida-Silva et al. (2012) também foram usados na comparação dos resultados do presente artigo. 
Após o lançamento dos dados na base de dados, os mesmos foram organizados no programa SPSS, o que possibilitou a confecção de quadros de frequências dos dados analisados.

Sendo assim, o presente estudo usa uma abordage qualitativa, considerando as variáveis propostas e estabelecendo-se comparações com artigos internacionais que apresentam a mesma temática.

\section{Análise e Discussão de Resultados}

Conforme já explicado no item anterior, o foco da análise proposta neste estudo é a metodologia utilizada pelos autores brasileiros que estudaram imagem de destinos turísticos. Foram, inicialmente identificadas as revistas científicas onde foram publicados estudos sobre o tema, bem como o ano de publicação. Estes dados possibilitaram a compreensão sobre onde estão a ser desenvolvidos os estudos sobre imagem de destinos turísticos.

A partir da análise do Quadro 4, é possível identificar que, o número de publicações no período de 2008-2014 se manteve estável em cada ano observado, destacando-se o ano de 2013 com seis publicações. Não se denotam significativas alterações no período considerado, sendo que a média de publicações é de 4 artigos. O periódico brasileiro com maior número de artigos publicados sobre o tema é a revista "Turismo em Análise”, seguido da revista "Observatório de Inovação do Turismo".

Em relação ao objeto de estudo, destaca-se a "Imagem do Brasil" (4 do total de 28). Outro aspeto a ressaltar é o número elevado de estudos (metade dos artigos) que se dedicam a compreender a imagem de municípios brasileiros, localizados em diferentes regiões. Dos municípios analisados cabe citar Curitiba (PR) (03 estudos), Natal (RN) (03 estudos), São Paulo (SP) (02 estudos), Rio de Janeiro (RJ) (02 estudos), Fortaleza (CE), Itu (SP), Ouro Preto (MG) e São Sebastião (SP) (01 estudo cada). Ainda é relevante destacar que três estudos analisados se focaram nas praias nordestinas e um no estado do Rio Grande do Norte. Estes resultados são similares aos de Gallarza et al. (2002), que identificaram que a maioria dos artigos analisados tinham como foco a análise de países e municípios em diferentes partes do mundo. 
Quadro 4 - Características das publicações analisadas

\begin{tabular}{|c|c|c|c|}
\hline Periódico de Publicação & Frequência & $\begin{array}{l}\text { Modelo e/ou Teoria } \\
\text { utilizada }\end{array}$ & Frequência \\
\hline Turismo em Análise & 6 & Não evidenciou & 17 \\
\hline $\begin{array}{l}\text { Observatório de Inovação do } \\
\text { Turismo }\end{array}$ & 4 & $\begin{array}{l}\text { Modelos de Formação de } \\
\text { Imagem (Beerli e Martin, } \\
\text { 2004) }\end{array}$ & 2 \\
\hline Caderno Virtual de Turismo & 3 & $\begin{array}{l}\text { Modelo de Formação de } \\
\text { Imagem (Chi e Qu, 2008) }\end{array}$ & 2 \\
\hline Cultur & 3 & $\begin{array}{l}\text { Comportamento do } \\
\text { Consumidor }\end{array}$ & 1 \\
\hline Turismo Visão e Ação & 3 & $\begin{array}{l}\text { Desenvolvimento } \\
\text { Sustentável e Atributos de } \\
\text { Imagem }\end{array}$ & 1 \\
\hline RBTur & 3 & Discurso do Sujeito Coletivo & 1 \\
\hline Revista Hospitalidade & 2 & Echtner e Ritchie (1991) & 1 \\
\hline Rosa dos Ventos & 2 & $\begin{array}{l}\text { Formação da Imagem } \\
\text { Turística (TDI) }\end{array}$ & 1 \\
\hline $\begin{array}{l}\text { Revista Eletrônica de } \\
\text { Turismo Cultural }\end{array}$ & 1 & Index Anholdt & 1 \\
\hline Turismo \& Sociedade & 1 & Visão Baseada em recursos & 1 \\
\hline Rosa dos Ventos & 2 & & \\
\hline Objeto de estudo & $\begin{array}{l}\text { Frequência } \\
\text { absoluta }\end{array}$ & Ano & $\begin{array}{l}\text { Frequência } \\
\text { Absoluta }\end{array}$ \\
\hline País (Brasil) & 4 & 2008 & 4 \\
\hline $\begin{array}{l}\text { Município (Curitiba, Natal, } \\
\text { Rio de Janeiro, São Paulo, } \\
\text { Fortaleza, Itu, Ouro Preto, } \\
\text { São Sebastião) } \\
\end{array}$ & 14 & 2009 & 4 \\
\hline $\begin{array}{l}\text { Praias (Jericoacara, Canoa } \\
\text { Quebrada) }\end{array}$ & 3 & 2010 & 4 \\
\hline Estado & 1 & 2011 & 2 \\
\hline \multirow[t]{3}{*}{ Estudos conceituais } & 6 & 2012 & 5 \\
\hline & & 2013 & 6 \\
\hline & & 2014 & 3 \\
\hline
\end{tabular}

Fonte: elaboração própria.

No que se refere aos modelos que serviram de base para o estudo, o resultado é similar ao identificado na publicação de Scalabrini et al. (2014), que verificou que a maioria dos estudos não menciona o modelo em que o estudo foi baseado. Rejowski (2010), também já havia identificado o mesmo nas publicações brasileiras ao afirmar que os estudos desenvolvidos no Brasil ainda apresentam distanciamento em relação ao referencial teórico e metodológico dos estudos realizados à escala internacional. Nos estudos analisados fica evidente que, os que se basearam em outros modelos e/ou teorias, aplicaram modelos internacionais na realidade brasileira. 
O Quadro 5 apresenta a metodologia utilizada nos vinte e oito artigos analisados. É importante destacar que, contrariamente ao que foi identificado no estudo de Scalabrini et al. (2014) que analisou as publicações sobre o tema de percepção de residentes, os estudos que abordam a imagem de destinos turísticos, têm um capítulo de metodologia melhor descrito, conforme será demonstrado no decorrer desta discussão.

Quadro 5 - Metodologia utilizada nos artigos analisados ${ }^{5}$

\begin{tabular}{|c|c|c|c|}
\hline Natureza do Estudo & $\begin{array}{l}\text { Frequência } \\
\text { absoluta }\end{array}$ & Abordagem Adotada & $\begin{array}{c}\text { Frequência } \\
\text { absoluta }\end{array}$ \\
\hline Empírico & 23 & Qualitativa & 9 \\
\hline \multirow[t]{3}{*}{ Conceitual } & 5 & Quantitativa & 8 \\
\hline & & Mista & 3 \\
\hline & & Não evidenciou & 8 \\
\hline Tipo de Pesquisa & $\begin{array}{l}\text { Frequência } \\
\text { absoluta }\end{array}$ & Técnica de Recolha dos Dados & $\begin{array}{c}\text { Frequência } \\
\text { absoluta }\end{array}$ \\
\hline Antropológico & 1 & Conteúdo de cartões postais & 1 \\
\hline Bibliográfico & 3 & Análise do discurso & 1 \\
\hline Descritivo & 2 & Análise de textos & 1 \\
\hline Descritivo-Analítico & 1 & Bibliografia & 5 \\
\hline Exploratório & 4 & Dados secundários & 1 \\
\hline Exploratório-descritivo & 6 & Documentos & 4 \\
\hline \multirow[t]{4}{*}{ Não evidenciou } & 11 & Entrevista & 4 \\
\hline & & Materiais iconográficos & 1 \\
\hline & & Questionário & 10 \\
\hline & & Não evidenciou & 1 \\
\hline Tipo de Amostra & $\begin{array}{l}\text { Frequência } \\
\text { absoluta }\end{array}$ & Forma de Análise dos Dados & $\begin{array}{c}\text { Frequência } \\
\text { absoluta }\end{array}$ \\
\hline Probabilística & 2 & Análise comparativa & 1 \\
\hline Não probabilística & 2 & Análise das entrevistas & 1 \\
\hline Aleatória simples & 1 & Análise de práticas discursivas & 1 \\
\hline \multirow[t]{10}{*}{ Não aleatória } & 1 & Análise de regressão múltipla & 3 \\
\hline & & Análise descritiva & 6 \\
\hline & & Análise fatorial exploratória & 4 \\
\hline & & Análise multivariada & 5 \\
\hline & & Cluster não hierárquico & 1 \\
\hline & & Equações estruturais & 1 \\
\hline & & Frequência dos dados & 1 \\
\hline & & Observação direta & 1 \\
\hline & & Testes de correlação & 1 \\
\hline & & $\begin{array}{l}\text { Teste da soma da ordem de } \\
\text { Wilcoxon }\end{array}$ & 1 \\
\hline
\end{tabular}

Fonte: elaboração própria.

No Brasil, as publicações na área do turismo ainda carecem de melhor rigor no que diz respeito aos aspectos metodológicos. Esta ilação é corroborada por Leal (2001) quando afirma que a

\footnotetext{
${ }^{5}$ Cabe destacar que alguns estudos utilizaram duas técnicas diferenciadas para a coleta dos dados e, por este motivo a soma das frequências não coincide com os 28 documentos analisados.
} 
pesquisa em turismo no Brasil ainda apresenta um baixo rigor científico, um baixo espírito crítico e ainda carece de domínio metodológico. Embora os artigos referentes à imagem tenham um melhor aprofundamento metodológico do que outros temas de estudo do turismo, na análise dos artigos selecionados ainda fica evidente a afirmação de Leal (2001). Efetivamente alguns artigos não deixaram claro como foi o procedimento metodológico utilizado para se chegar aos objetivos. Por seu turno, os estudos de caráter quantitativo descreveram a metodologia e foram mais além da estatística descritiva, como pode ser observado no item "Forma de análise dos dados", no Quadro 5.

É interessante observar que, no período analisado, Chagas é um dos autores que mais publicou sobre a temática de imagem de destinos turísticos, seja individualmente ou com outros autores. Outro autor que também se destaca é Gândara.

Sobre a abordagem das publicações, o Quadro 6 apresenta os autores que trabalharam com cada uma das abordagens.

Quadro 6 - Abordagem das publicações analisadas

\begin{tabular}{l|l}
\hline \multicolumn{1}{c|}{ Abordagem } & \multicolumn{1}{c}{ Autores } \\
\hline Conceitual & (CHAGAS, 2008; GÂNDARA, 2008; CHAGAS, 2009; BREA e CARDOSO, 2011; \\
& PINTO, 2012) \\
\hline Quantitativa & (MAZZON e VERA, 2008; CHAGAS e MARQUES JÚNIOR, 2010; MARIUTTI e \\
& GIRALDI, 2012; BUOSI e LEOCÁDIO, 2013; CAMPOS JÚNIOR, et al., 2013; \\
& CHAGAS, et al., 2013a; CHAGAS, et al., 2013b; BUOSI, et al., 2014) \\
\hline Qualitativa & (CHAGAS e DANTAS, 2009; MACIEL, 2009; KAJIHARA, 2010; SIQUEIRA, \\
& 2010; CARNIELLO e SANTAELLA, 2012; GOMES, 2012; FERNANDES, et al., \\
& 2013; MANOSSO, et al., 2013; SOUZA e DE CARVALHO, 2014) \\
\hline Quali-Quantitativa & (FIGUEIRÊDO e MAYER, 2010; MACHADO e GOSLING, 2010; NEIMAN, et \\
& al., 2011) \\
\hline
\end{tabular}

Fonte: elaboração própria.

Ainda em relação à metodologia, foi possível identificar que a maioria dos estudos (vinte e três) tem caráter empírico, sendo essencialmente de abordagem qualitativa (nove). Nas publicações sobre esta temática identificou-se um número superior à temática de percepção de residentes que trabalha com a abordagem quantitativa. Estes resultados são similares ao de Kovacs et al. (2012), onde foi identificado que 97,6\% dos artigos analisados eram de caráter empírico e $79,8 \%$ usavam uma abordagem qualitativa.

É importante salientar que o número de artigos que não aborda a tipologia de pesquisa ainda é relevante, se considerado o número de publicações analisadas. 
Sobre a coleta de dados, os estudos de abordagem qualitativa utilizaram entrevistas, análise de textos, documentos, fotografias e websites. Os estudos de abordagem quantitativa utilizaram questionários, a maioria baseados em estudos internacionais, como o de Echtner e Ritchie (2003), e a estrutura do questionário era composto por afirmações seguidos de uma escala de Likert, geralmente de cinco níveis.

Considerando os estudos quantitativos, diferentes foram as metodologias utilizadas para a interpretação dos dados, evidenciando-se a análise descritiva, seguida da multivariada e fatorial. Em relação às publicações brasileiras analisadas, fica evidente que, ainda é necessário um maior aprofundamento em relação às técnicas estatísticas. Os estudos internacionais sobre este tema trabalham basicamente a abordagem quantitativa e a interpretação dos dados é feita por meio de procedimentos estatísticos mais complexos como os métodos multivariados análise fatorial, análise de componentes principais, análise de clusters, regressão múltipla, análise de variância (GALLARZA, et al., 2002).

Ainda sobre os artigos que apresentaram uma abordagem quantitativa e mista, a média de amostragem foi de 260 , sendo que a menor amostra correspondeu a 38 respondentes e a maior amostra a 622 respondentes. Esta média é similar aos trabalhos internacionais.

No que diz respeito à utilização de publicações internacionais para a realização de estudos percebe-se que os pesquisadores brasileiros buscam a utilização de referências de periódicos internacionais. Esta afirmação pode ser comprovada nos vinte e oito artigos analisados. Em termos médios constatou-se que foram citados aproximadamente vinte referências internacionais e 14 referências brasileiras em cada artigo.

\section{Considerações Finais}

Considerando que o principal objetivo deste artigo era analisar os aspectos metodológicos das publicações brasileiras que abordavam o tema de imagem de destinos turísticos e compará-los com estudos internacionais, foi possível identificar que, assim como o tema de percepção de residentes, alguns aspectos metodológicos devem ser melhor aprofundados nas publicações brasileiras.

Em relação ao objeto de pesquisa é interessante observar o número de estudos realizados na cidade de Curitiba (PR), visto não ser um dos principais pontos turísticos do país. Este destaque 
tem sido desenvolvido por Gândara, da Universidade Federal do Paraná, que foi um dos autores que possui um maior número de publicações analisadas. Outra ilação é o número de artigos que buscam identificar a imagem do Brasil. Durante muito tempo a imagem do país esteve relacionada com as belezas naturais, com o futebol e com o carnaval e muito centrada na imagem das mulheres belas (GOMES, 2012). Atualmente a Embratur busca reposicionar a imagem do Brasil, e Gomes (2012) comprovou isso recentemente, ao analisar o Plano Aquarela e identificar que já há um esforço para mostrar um Brasil com outras opções.

Sobre as questões metodológicas, a partir da análise é notória a necessidade de uma maior preocupação com as técnicas quantitativas. Embora os estudos analisados utilizem ferramentas estatísticas mais avançadas, ainda é evidente um número de artigos utilizando somente uma abordagem qualitativa. Isso não significa que este método não é relevante, mas muitas vezes os estudos são assim classificados, por que não tiveram um tratamento estatístico adequado e/ou porque o pesquisador acredita que esta abordagem é mais fácil (KOVACS, et al., 2012). Ao analisar os estudos internacionais, a maioria destes faz uma abordagem quantitativa e busca responder aos seus objetivos de pesquisa por meio de ferramentas estatísticas.

É importante evidenciar a utilização de referências internacionais para a fundamentação dos estudos nacionais. Ao abordar a imagem de destinos turísticos, foi perceptível que a maioria dos artigos analisados citaram autores internacionais, destacando-se Gallarza et al. (2002) e Echtner e Ritchie (2003).

Por último, não se pode olvidar que os estudos de revisão de literatura podem auxiliar futuros pesquisadores no desenvolvimento das suas pesquisas, pois podem ajudar a identificar lacunas existentes nas pesquisas já realizadas e sugerir novos estudos. Pensando na internacionalização de pesquisas, a análise de publicações brasileiras sobre o tema de imagem de destinos turísticos, pode aprofundar as pesquisas já existentes e propor a utilização de métodos de pesquisa já utilizados internacionalmente.

\section{Referências}

Alves, F. M. B. Avaliação da qualidade do espaço público urbano. Proposta Metodológica. Coimbra: Dinalivro, 2003

BALOGLU, S. E MCCLEARY, K. W. A model of destination image formation. Annals of tourism research. v. 26. n. 4. 1999. p. $868-897$ 
BREA, J. A. F. E CARDOSO, L. Tourism destination image: Reflexão sobre as principais investigações internacionais. CULTUR: Revista de Cultura e Turismo. v. 5. n. 2. 2011. p. 4-18

BreA, J. A. F. E CARDoso, L. Tourism Destination Image: Reflexão Sobre as Principais Investigações Internacionais. Revista de Cultura e Turismo. v. 2. n. 2011. p. 4-18

Buosi, M. C. E LeOCÁDIO, A. A Avaliação dos Atributos da Imagem e sua Relação com a Imagem Global do Destino de Turismo Internacional-Praia de Jericoacoara. Revista Turismo em Análise. v. 24. n. 1. 2013.p. $25-40$

Buosi, M. C. D. A. N., et al. A relação entre desenvolvimento sustentável e imagem de lugar de um destino turístico: proposição de um modelo estrutural. Revista Brasileira de Pesquisa em Turismo. v. 8. n. 2. 2014. p. 262-285

CAMPOS JÚNIOR, G. B., et al. Visão baseada em recursos versus imagem do destino: um estudo de estratégia a partir dos imóveis adquiridos por noruegueses no Rio Grande do Norte. Turismo-Visão e Ação. v. 15. n. 3. 2013. p. 340-353

Carniello, M. F. e Santaella, L. A. A imagem turística de São Sebastião (SP). Caderno Virtual de Turismo. v. 12. n. 3. 2012. p. 287-308

Chagas, M. Formação da Imagem de Destinos Turísticos: Uma Discussão dos Principais Modelos Internacionais. Caderno Virtual de Turismo. v. 9. n. 1. 2009. p. 117-127

ChagAS, M. M. D. Imagem de destinos turísticos: Uma discussão teórica da literatura especializada. Turismo-Visão e Ação. v. 10. n. 3. 2008. p. 435-455

Chagas, M. M. D. E Dantas, A. V. S. A imagem do Brasil como destino turístico nos websites das operadoras de turismo européias. Revista Acadêmica Observatório de Inovação do Turismo. v. 4. n. 2. 2009. p. $1-19$

Chagas, M. M. D. E MARQueS JÚNIOR, S. Análise da relação causal entre imagem, qualidade, satisfação e fidelidade: um estudo sobre a percepção do turista nacional no destino turístico Natal/RN. Revista Turismo em Análise. v. 21. n. 3. 2010. p. 494-516

Chagas, M. M. D., et al. Análise do processo de formação da imagem de destinos turísticos de sol e praia: um estudo em Canoa Quebrada/CE. Revista Brasileira de Pesquisa em Turismo. v. 7. n. 3. 2013 a. p. $456-475$

Chagas, M. M. D., et al. Análise da influência da imagem de destinos na satisfação e fidelidade a destinações de turismo de sol e praia: Um estudo em Natal/RN. Revista Brasileira de Pesquisa em Turismo. v. 7. n. 2. 2013b. p. 296-316

CHOI, S., et al. Destination image representation on the web: Content analysis of Macau travel related websites. Tourism Management. v. 28. n. 1. 2007. p. 118-129

ECHTNER, C. M. E RitCHIE, J. B. The meaning and measurement of destination image. The Journal of Tourism Studies. v. 14. n. 1. 2003. p. 37-48

FERNANDES, D. L., et al. A paisagem urbana e a formação da imagem turística da cidade de Curitiba/PR: a percepção de visitantes e visitados. Revista Hospitalidade. v. n. 1. 2013. p. 45-63

Figueirêdo, A. A. E MAYer, V. F. A Imagem dos Destinos Turísticos: a cidade de São Paulo sob o olhar de jovens do Rio de Janeiro. Revista Turismo em Análise. v. 21. n. 3. 2010. p. 445-469

FreITAG, B. B., et al. A produção acadêmica em turismo no campo da administração. Turismo-Visão e Ação. v. 13. n. 2. 2011. p. 260-273

Gallarza, M. G., et al. Destination image: Towards a conceptual framework. Annals of Tourism Research. v. 29. n. 1. 2002. p. 56-78 
GÂndarA, J. M. G. A Imagem dos Destinos Turísticos Urbanos. Revista Eletrônica de Turismo Cultural. v. Especial. n. 2008. p. 1-22

GOMES, M. S. A imagem do Brasil no exterior e o turismo: a operacionalização do Plano Aquarela em Portugal. Rosa dos Ventos-Turismo e Hospitalidade. v. 4. n. 4. 2012. p. 506-521

KAJIHARA, K. A. A Imagem do Brasil no Exterior: Análise do material de divulgação oficial da EMBRATUR, desde 1966 até 2008. Revista Acadêmica Observatório de Inovação do Turismo. v. n. 3. 2010. p. 05 a 05

Kovacs, M., et al. Pesquisa em Turismo: Uma Avaliação das Metodologias Empregadas nos Artigos Publicados nos Anais no Triênio do Seminário Anual da Associação Brasileira de Pesquisa e PósGraduação em Turismo - ANPTUR. Turismo-Visão e Ação. v. 14. n. 1. 2012. p. 19-34

LEAL, E. J. M. Pesquisa e Produção Escrita. Turismo-Visão e Ação. v. 4. n. 8. 2001. p. 99-110

Machado, D. F. C. E Gosling, M. A imagem do destino turístico Ouro Preto e seus reflexos na lealdade, na satisfação e na divulgação boca a boca. Revista Acadêmica Observatório de Inovação do Turismo. v. 5. n. 3. 2010. p. 1-28

MACIEL, W. R. N. Fortaleza: imagem urbana, cidade e turismo. Revista Acadêmica Observatório de Inovação do Turismo. v. n. 1. 2009. p. 1-15

MANOsso, F. C., et al. A Imagem da Cidade em Fotografias Online: Estudo de Caso do Site Flickr sobre Curitiba (Paraná, Brasil). Turismo e Sociedade. v. 6. n. 4. 2013. p. 835-860

MariutTI, F. G. E GiRALDI, J. D. M. E. Análise da Imagem do Brasil por meio do Anholt Nation Branging Index. Turismo-Visão e Ação. v. 14. n. 1. 2012. p. 67-81

Mazzon, J. A. E VerA, L. A. N. A opinião dos turistas de negócios sobre a Imagem da Cidade de São Paulo. Revista Turismo em Análise. v. 19. n. 3. 2008. p. 345-368

NeIMAN, Z., et al. A imagem como agente motivador para o ecoturismo. Revista Turismo em Análise. v. 22. n. 1. 2011. p. 71-95

Panosso Netto, A. e De Mello Calciolari, G. F. Quantos são os Livros Teóricos de Turismo Publicados no Brasil? Uma Análise da Produção Bibliográfica Nacional (1990-2010). Revista Turismo em Análise. v. 21. n. 3. 2011. p. 668-686

PÉREZ, X. P. Turismo cultural: uma visão antropológica. Asociación Canaria de Antropología, 2009

PINTO, R. A Formação das Imagens no Turismo: itinerário teórico e proposta de um modelo operacional. Revista Turismo em Análise. v. 23. n. 3. 2012. p. 552-574

REJOWSKI, M. Produção Científica em Turismo: análise de estudos referenciais no exterior e no Brasil. Revista Turismo em Análise. v. 21. n. 2. 2010. p. 224-246

Rosvadoski-DA-Silva, P., et al. Uma Análise da Produção Científica nos Periódicos de Turismo sobre o Tema Comportamento do Consumidor em Turismo. Turismo-Visão e Ação. v. 14. n. 1. 2012. p. 047066

RYAN, C. E AICKEN, M. The destination image gap - visitors' and residents' perceptions of place: evidence from Waiheke Island, New Zealand. Current Issues in Tourism. v. 13. n. 6. 2010. p. 541-561

SCALABRINI, E. C. B., et al. Perceções de residentes a respeito dos impactes da atividade turística: Uma análise das publicações brasileiras sobre o tema. Tourism and Hospitality International Journal. v. 2. n. 2. 2014. p. 12-31

SIQUEIRA, E. D. D. Turismo, Imagem e Cultura: Representações sociais do Estado e do Poder nos cartões-postais da cidade do Rio de Janeiro. Rosa dos Ventos - Turismo e Hospitalidade. v. 1. n. 2010. p. $1-11$ 
SouzA, A. M. E DE CARvalho, A. N. O comércio de souvenires e sua relação com a imagem da destinação: um estudo na cidade de Itu/SP. Revista Hospitalidade. v. n. 1. 2014. p. $64-89$

Vareiro, L. C. E Ribeiro, J. A. C. A imagem de destino e o potencial turístico do Vale do Minho (Portugal). XXII Reunión de Estudiós Regionales. v. n. 2006. p. 1-28

\section{Recebido em: 15/06/2015}

Aprovado em: 20/07/2015 